Jurnal Keperawatan Silampari

Volume 4, Nomor 2, Juni 2021

e-ISSN: 2581-1975

p-ISSN: 2597-7482

DOI: https://doi.org/10.31539/jks.v4i2.1935

\title{
INTERVENSI HEALTH COACHING DALAM MENINGKATKAN SELF-CARE MANAGEMENT PASIEN HEART FAILURE
}

\author{
Asriyani Hamid ${ }^{1}$, Elly L. Sjattar ${ }^{2}$, Kusrini S. Kadar ${ }^{3}$ \\ Universitas Hasanuddin ${ }^{1,2,3}$ \\ ellyunhas@gmail.com²
}

\begin{abstract}
ABSTRAK
Penelitian ini bertujuan untuk mengidentifikasi literatur yang mengeksplorasi intervensi pembinaan kesehatan dalam meningkatkan manajemen perawatan diri Heart Failure (HF) yang berfokus pada jumlah durasi dan jenis media pembinaan kesehatan. Metode penelitian menggunakan literatur review dengan menelusuri hasil publikasi antara tahun 2017-2020, database Cochrane, PubMed, ScienceDirect, ProQuest, dan Garuda. Hasil penelitian mengidentifikasi lima studi pembinaan kesehatan sesuai kriteria inklusi dan menghasilkan peningkatan signifikan pada manajemen perawatan diri HF, termasuk pelaporan gejala, peningkatan aktivitas fisik, diet rendah garam, asupan cairan dan obat, efikasi diri, kepatuhan mengukur berat badan dan tekanan darah, serta perubahan gaya hidup, meskipun terdapat perbedaan metode pembinaan kesehatan yang digunakan. Simpulan, jumlah durasi dan media yang berbeda dari setiap studi tidak berpengaruh secara signifikan pada hasil peningkatan manajemen perawatan diri HF.
\end{abstract}

Kata Kunci: Heart Failure, Manajemen Perawatan Diri, Pembinaan Kesehatan

\section{ABSTRACT}

This study aims to identify the literature that explores health coaching interventions in improving Heart Failure (HF) self-care management, focusing on the total duration and type of health coaching media. The research method uses literature reviews by tracing publications between 2017-2020, the Cochrane database, PubMed, ScienceDirect, ProQuest, and Garuda. The results identified five health coaching studies according to inclusion criteria and resulted in significant improvements in HF self-care management, including symptom reporting, increased physical activity, lowsalt diet, fluid and drug intake, self-efficacy, adherence to measuring body weight and blood pressure, and changes. Lifestyle, even though there are differences in the health training methods used. In conclusion, the duration and different media from each study did not significantly influence improving $\mathrm{HF}$ self-care management.

Keywords: Heart Failure, Self-Care Management, Health Development

\section{PENDAHULUAN}

Heart Failure (HF) merupakan sindrom klinis yang disebabkan oleh kelainan struktural dan fungsional jantung, dimana jantung tidak mampu dalam memompa darah dan oksigen ke seluruh tubuh untuk memenuhi kebutuhan metabolisme sampai ke jaringan perifer (Rossignol et al., 2019). Heart Failure menjadi tahap akhir dari semua penyakit kardiovaskuler (Crespo-Leiro et al., 2018). Prevalensi morbiditas dan mortalitas 
HF semakin meningkat sekitar 26 juta jiwa di seluruh dunia, Amerika Serikat merupakan salah satu negara maju telah mencapai 6,2 juta orang dengan HF (Benjamin et al., 2019). Indonesia sendiri memiliki data prevalensi penyakit jantung mencapai $1,5 \%$ untuk semua umur dan berdasarkan diagnosa dokter (Riskesdas, 2018). Berdasarkan prevalensi, peningkatan morbiditas dan mortalitas HF dengan distribusi yang tidak merata memberikan tantangan sangat besar terhadap perawatan kesehatan.

Penyebab kematian HF diperkirakan meningkat pada tahun 2030 (Sevilla-Cazes et al., 2018). Kondisi kesehatan semakin memburuk merupakan salah satu penyebab yang dapat dicegah dengan meningkatkan kepatuhan terhadap pedoman HF (Di Palo et al., 2018). Self-care management merupakan tindakan non farmakologik yang berhubungan dengan tingkat kepatuhan pasien, terutama terhadap pengobatan dan diet rendah natrium, dimana pendidikan pasien yang dipersonalisasi dianggap lebih relevan dalam memotivasi dan mempengaruhi pasien dalam mengubah perilaku (Athar et al., 2018).

Penyedia layanan kesehatan telah melakukan berbagai upaya pendidikan kesehatan dengan berbagai metode dan media yang digunakan, termasuk intervensi konvensional dan program pendidikan atau promosi kesehatan, seperti program pendidikan yang dilakukan secara individual menggunakan media slide PowerPoint, gambar, video klip, dan buku edukasi yang berisikan HF (Abbasi et al., 2018) danprogram pendidikan dan promosi kesehatan dengan menggunakan material booklet dan DVD (Artama et al., 2017; Boyde et al., 2017). Namun, dari studi tersebut yang menggunakan metode dan media pendidikan kesehatan yang berbeda, didapatkan bahwa penerapan intervensi pendidikan kesehatan masih memerlukan penelitian lanjut untuk menentukan metode yang tepat (termasuk durasi dan metode tindak lanjut). Selain itu, perubahan perilaku pasien tidak nampak setelah diberikan pendidikan kesehatan, karena tidak adanya umpan balik atau kesempatan yang diberikan untuk mengungkapkan informasi kesehatan apa yang sebenarnya dibutuhkan oleh pasien (Hastuti, 2019). Penyedia layanan kesehatan mengakui pentingnya self-care management dilakukan secara menyeluruh dengan melibatkan pasien dalam proses secara langsung (Riegel et al., 2017). Oleh karena itu, diperlukan pendekatan lain dalam bentuk intervensi seperti health coaching yang merupakan bidang baru dan berfokus pada masalah kesehatan pasien.

Health coaching sebagai salah satu konsep baru yang menerapkan kemitraan yang berorientasi pada tujuan dan berpusat pada pasien yang berfokus pada kesehatan melalui proses pemberdayaan (Hale \& Giese, 2017). Health coaching sangat menjanjikan bagi individu dengan HF yang sering menunjukkan perburukan tanda dan gejala, sebelum mencari bantuan penyedia layanan kesehatan dan rawat inap.

Health coaching dapat meningkatkan hasil klinis dan self-care management pasien dengan penyakit kronik termasuk HF (Dye et al., 2018). Health coaching meningkatkan kondisi fisiologis dan psikologis, perubahan perilaku, hasil klinis, dan status kesehatan pasien (Veen et al., 2017). Health coaching telah terbukti sebagai intervensi bagi penyedia layanan kesehatan untuk meningkatkan self-care management pasien HF, dimana diperlukan individu dengan HF secara konsisten melakukan perubahan perilaku dan tindakan mandiri harian bersama dengan pengetahuan dan kemampuan dalam mengambil keputusan perawatan yang tepat untuk gejala yang dialami. Namun, efek komponen yang digunakan dalam health coaching masih belum jelas. Penting untuk mengetahui pengaruh yang dihasilkan oleh intervensi health coaching, termasuk komponen health coaching harus diidentifikasi secara jelas mana yang memiliki pengaruh terhadap tujuan (Dejonghe et al., 2017). 
Sebelumnya telah dilakukan tinjauan sistematis meta-analisis yang berfokus pada metode health coaching yang berusaha menganalisis efektifitas intervensi dalam meningkatkan kualitas hidup, perilaku self-care management (termasuk kepatuhan berobat, aktivitas fisik, perilaku merokok, diet) dan manajemen stres (An \& Song, 2020), dan tinjauan sistematis yang membahas tentang efektifitas health coaching yang menghasilkan efek yang lebih besar pada tingkat aktivitas fisik pasien dengan penyakit kronik termasuk HF (Oliveira et al., 2017). Namun, dari kedua tinjauan tersebut tidak menampakkan hasil maksimal, dikarenakan populasi yang berbeda, keragaman pendekatan intervensi, kurangnya detail komponen intervensi, dan keragaman hasil.

\section{METODE PENELITIAN}

Studi menggunakan metode literatur review dengan menelusuri hasil publikasi ilmiah dalam rentang waktu antara tahun 2017 hingga 2020 dengan menggunakan 5 database yaitu; Cochrane Library, PubMed, ScienceDirect, Proquest, dan Garuda. Strategi pencarian berdasarkan $\mathrm{PICO}$ /Patient, Intervention, Comparison, and Outcome (Eriksen \& Frandsen, 2018), dengan kata kunci: P: Heart Failure OR congestive Heart Failure OR chronic Heart Failure OR adult > 18 years, I: health coaching OR telephone coaching OR motivational interviewing, C: No Intervention, Control, Standart Care, O: self-care management OR self-care.

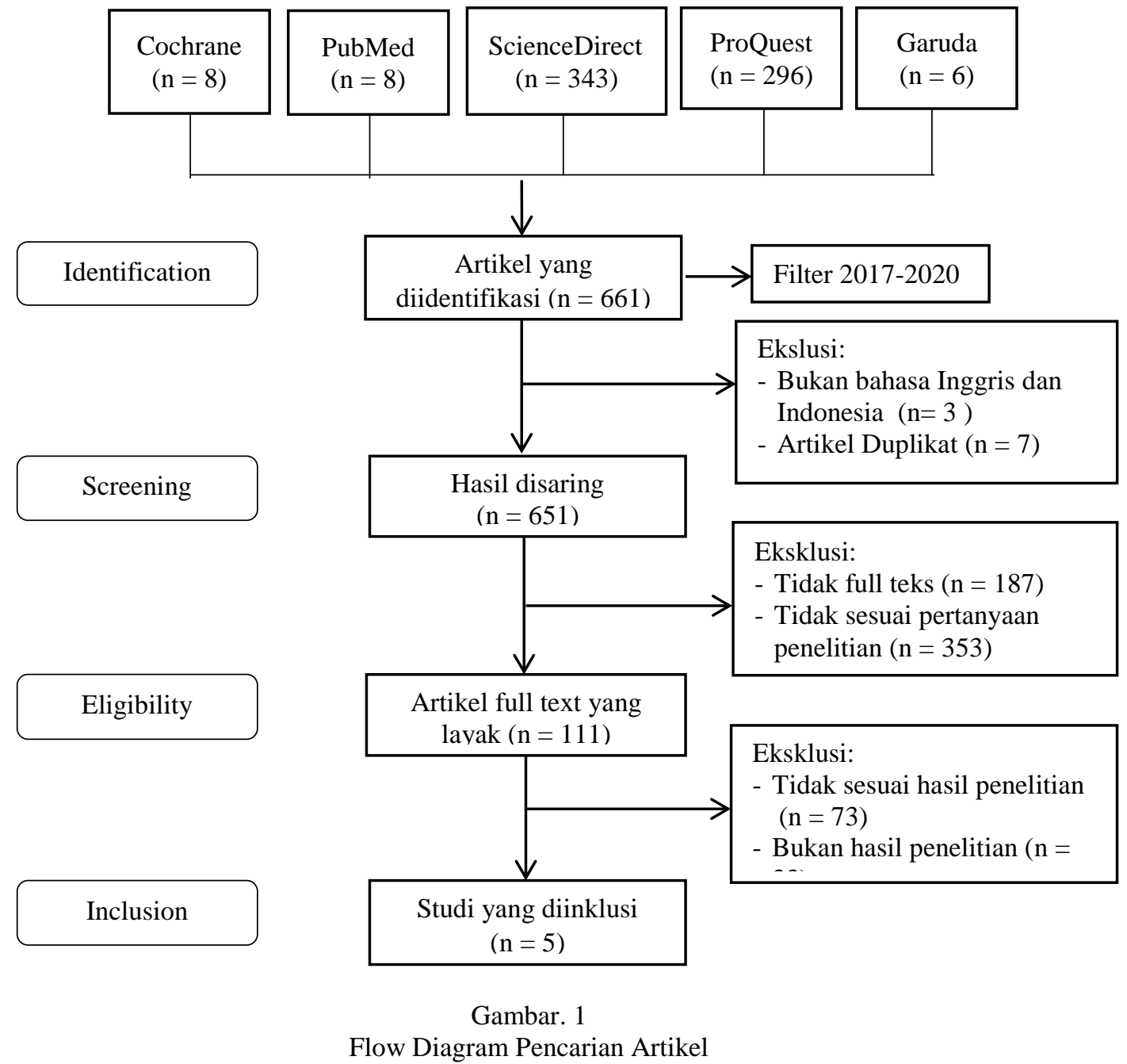


Pencarian terbatas pada artikel penelitian yang dilakukan pada orang dewasa dan ditulis dalam bahasa Inggris dan bahasa Indonesia. Pencarian ini menghasilkan 661 artikel, tujuh artikel di antaranya di eksklusi karena duplikat dan tiga artikel bukan dalam bahasa Inggris dan Indonesia. Hasil skrining diidentifikasi lima artikel yang memenuhi kriteria inklusi dan relevan atau sesuai pertanyaan penelitian (Gambar 1). Semua abstrak dievaluasi untuk kriteria inklusi dan eksklusi.

Kriteria inklusi dalam tinjauan literatur ini antara lain 1) Pasien dengan Heart Failure dengan usia $\geq 18$ tahun, 2) Intervensi yang digunakan adalah health coaching, 3) Hasil penelitian menunjukkan peningkatan self-care management. Sedangkan kriteria eksklusi antara lain 1) Artikel duplikat, 2) Bukan dalam bahasa Inggris dan Indonesia, 3) Tidak full teks, 4) Artikel tidak terbuka, 5) Tidak sesuai pertanyaan penelitian, dan 6) Bukan hasil penelitian. Studi yang tidak memasukkan self-care management pasien HF sebagai hasil dikeluarkan. Kriteria inklusi pada tinjauan ini termasuk komponen pelaksanaan health coaching.

\section{HASIL PENELITIAN}

Tabel. 1

Deskripsi Studi yang Termasuk dalam Review

\begin{tabular}{|c|c|c|c|c|}
\hline No & $\begin{array}{l}\text { Pengarang, Judil, } \\
\text { Jenis Literatur }\end{array}$ & Tahun & Tujuan & Hasil \\
\hline 1 & $\begin{array}{l}\text { Dwinger et al., } \\
\text { Effects Of } \\
\text { Telephone-Based } \\
\text { Health Coaching } \\
\text { On Patient- } \\
\text { Reported } \\
\text { Outcomes And } \\
\text { Health Behavior } \\
\text { Change: A } \\
\text { Randomized } \\
\text { Controlled Trial, } \\
\text { Randomized } \\
\text { Controlled Trial }\end{array}$ & 2020 & $\begin{array}{l}\text { Penelitian ini } \\
\text { bertujuan } \\
\text { untuk } \\
\text { mengetahui } \\
\text { Pengaruh } \\
\text { Pelatihan } \\
\text { Kesehatan } \\
\text { Berbasis } \\
\text { Telepon Pada } \\
\text { Hasil Yang } \\
\text { Dilaporkan } \\
\text { Pasien dan } \\
\text { Perubahan } \\
\text { Perilaku } \\
\text { Kesehatan }\end{array}$ & $\begin{array}{l}\text { Kelompok TBHC secara statistik } \\
\text { signifikan lebih tinggi dibanding } \\
\text { kelompok kontrol: Aktivitas fisik } \\
\text { dalam jam per minggu }(\mathrm{p}=.030) \text {. } \\
\text { Tingkat metabolisme per minggu } \\
(\mathrm{p}=.048) \text {. BMI }(\mathrm{p}=0.009) \text {. } \\
\text { Kepatuhan pengukuran tekanan } \\
\text { darah }(\mathrm{p}<0.001) \text {. Aktivasi pasien } \\
(\mathrm{p}<0.001) \text {. Literasi kesehatan }(\mathrm{p} \\
<0.001) . \text { Kualitas hidup fisik }(\mathrm{p}= \\
0.441)\end{array}$ \\
\hline 2 & $\begin{array}{l}\text { Vellone et al., } \\
\text { Motivational } \\
\text { interviewing to } \\
\text { improve self- } \\
\text { care in Heart } \\
\text { Failure patients } \\
\text { (MOTIVATE- } \\
\text { HF): a } \\
\text { randomized } \\
\text { controlled trial, } \\
\text { Randomized } \\
\text { Controlled Trial }\end{array}$ & 2020 & $\begin{array}{l}\text { Penelitian ini } \\
\text { bertujuan } \\
\text { untuk } \\
\text { meningkatkan } \\
\text { perawatan diri } \\
\text { pada pasien } \\
\text { gagal jantung } \\
\text { (MOTIVATE- } \\
\text { HF) melalui } \\
\text { wawancara } \\
\text { motivasi }\end{array}$ & $\begin{array}{l}\text { Skor pemeliharaan perawatan diri } \\
\text { yang memadai }(\geq 70) \text { secara } \\
\text { signifikan lebih tinggi }(\mathrm{p}= \\
0,0282) \\
\text { Skor manajemen perawatan diri di } \\
\text { tiga kelompok secara signifikan } \\
\text { lebih tinggi di kelompok } 1 \text { dan } 2 \\
\text { daripada kelompok } 3(\mathrm{p}=0.028 \\
\text { dan } \mathrm{p}=0.0076) \\
\text { Skor kepercayaan perawatan diri } \\
\text { tidak ada perbedaan secara } \\
\text { signifikan pada ketiga kelompok }\end{array}$ \\
\hline 3 & $\begin{array}{l}\text { Meeker et al., } \\
\text { Patient } \\
\text { Commitment to } \\
\text { Health ( PACT- }\end{array}$ & 2019 & $\begin{array}{l}\text { Penelitian ini } \\
\text { bertujuan } \\
\text { untuk } \\
\text { mengetahui }\end{array}$ & $\begin{array}{l}\text { Pada kepatuhan berobat, sebagian } \\
\text { besar pasien merasa bahwa } \\
\text { kepatuhan bukanlah salah satu hal } \\
\text { yang serius untuk dilakukan }\end{array}$ \\
\hline
\end{tabular}




\begin{tabular}{|c|c|c|c|}
\hline & $\begin{array}{l}\text { Health ) in the } \\
\text { Heart Failure } \\
\text { Population : A } \\
\text { Focus Group } \\
\text { Study of an } \\
\text { Active } \\
\text { Communication } \\
\text { Framework for } \\
\text { Patient-Centered } \\
\text { Health Behavior } \\
\text { Change, } \\
\text { RCT }\end{array}$ & $\begin{array}{l}\text { Kerangka } \\
\text { Komunikasi } \\
\text { Aktif untuk } \\
\text { Perubahan } \\
\text { Perilaku } \\
\text { Kesehatan } \\
\text { yang Berpusat } \\
\text { pada Pasien }\end{array}$ & $\begin{array}{l}\text { karena menganggap bahwa dosis } \\
\text { rejimen sudah terjadwal dari } \\
\text { dokter sebelumnya } \\
\text { Kebiasaan latihan fisik, sebagian } \\
\text { besar pasien merasakan } \\
\text { keterbatasan signifikan dalam } \\
\text { kemampuan latihan fisik, namun } \\
\text { satu pasien melakukan latihan } \\
\text { rutin dikarenakan video tutorial } \\
\text { disediakan oleh dokternya } \\
\text { Kebiasaan diet, sebagian besar } \\
\text { pasien menerima hanya sedikit } \\
\text { bimbingan tentang diet dari } \\
\text { dokter mereka, namun satu pasien } \\
\text { menerima diet Mediterania } \\
\text { sebagai rekomendasi spesifik dari } \\
\text { dokternya }\end{array}$ \\
\hline 4 & $\begin{array}{l}\text { Michel Tiede et } 2017 \\
\text { al., } \\
\text { Long-Term } \\
\text { Effectiveness Of } \\
\text { Telephone-Based } \\
\text { Health Coaching } \\
\text { For Heart } \\
\text { Failure Patients: } \\
\text { A Post-Only } \\
\text { Randomised } \\
\text { Controlled Trial } \\
\text { Randomized } \\
\text { Controlled Trial }\end{array}$ & $\begin{array}{l}\text { Penelitian ini } \\
\text { bertujuan } \\
\text { untuk } \\
\text { mengetahui } \\
\text { Efektivitas } \\
\text { Jangka } \\
\text { Panjang } \\
\text { Pelatihan } \\
\text { Kesehatan } \\
\text { Berbasis } \\
\text { Telepon } \\
\text { Untuk Pasien } \\
\text { Gagal Jantung }\end{array}$ & $\begin{array}{l}\text { Hasil QoL tidak menunjukkan } \\
\text { hasil yang signifikan } \\
\text { Aktivitas fisik (p .034) } \\
\text { Asupan resep obat (p 0.04) } \\
\text { Tingkat stres (p 0.02) }\end{array}$ \\
\hline 5 & $\begin{array}{l}\text { Wang et al., } \\
\text { Effectiveness Of } \\
\text { A Precede-Based } \\
\text { Education } \\
\text { Intervention On } \\
\text { Quality Of Life } \\
\text { In Elderly } \\
\text { Patients With } \\
\text { Chronic Heart } \\
\text { Failure } \\
\text { Randomized } \\
\text { Controlled rial }\end{array}$ & $\begin{array}{l}\text { Penelitian ini } \\
\text { bertujuan } \\
\text { untuk } \\
\text { mengetahui } \\
\text { Efektivitas } \\
\text { Intervensi } \\
\text { Pendidikan } \\
\text { Berbasis } \\
\text { Sebelumnya } \\
\text { Terhadap } \\
\text { Kualitas } \\
\text { Hidup Pada } \\
\text { Penderita } \\
\text { Gagal Jantung } \\
\text { Kronis Lanjut } \\
\text { Usia }\end{array}$ & $\begin{array}{l}\text { Skor total terjadi penurunan } \\
\text { secara signifikan pada kelompok } \\
\text { intervensi dibandingkan } \\
\text { kelompok kontrol, kecuali pada } \\
\text { latihan secara teratur. } \\
\text { Intervensi PRECEDE } \\
\text { menunjukkan secara signifikan } \\
\text { meningkatkan perilaku perawatan } \\
\text { diri, penurunan gejala, skor fisik } \\
\text { dan emosional menurun pada } \\
\text { kedua kelompok dengan hasil } \\
\text { analisis korelasi Pearson yang } \\
\text { mengungkapkan skor MLHFQ } \\
\text { secara signifikan berkorelasi } \\
\text { dengan skor EHFScBS-9 (p } \\
<0,001 \text { ) dan PHQ-9 (p <0,001). }\end{array}$ \\
\hline
\end{tabular}

Berdasarkan tabel 1 menunjukkan bahwa lima studi yang termasuk dalam tinjauan literatur melaporkan bahwa health coaching meningkatkan beberapa atau semua aspek perawatan diri pasien dengan $\mathrm{HF}$, diantaranya melaporkan bahwa intervensi health coaching berbasis telepon melaporkan secara signifikan meningkatkan self-care management pasien dengan HF, dan satu artikel yang menggunakan tatap muka sebagai media intervensi secara signifikan meningkatkan kepatuhan berobat, kebiasaan latihan fisik, dan kebiasaan diet 
Intervensi health coaching meningkatkan self-care management secara signifikan terkait diet rendah garam, aktivitas fisik, kepatuhan pengukuran berat badan dan tekanan darah, kepatuhan pengobatan, perubahan perilaku menuju aktivitas lebih tinggi, tingkat stres yang menurun, peningkatan fungsi fisik, dan kemampuan melakukan perawatan diri.

\section{PEMBAHASAN}

Self-care management adalah suatu strategi yang digunakan untuk mengatasi kondisi kronis pasien dengan memberikan pendidikan kesehatan secara aktif dalam mengidentifikasi masalah dan menyelesaikan masalah kesehatannya (Grady \& Gough, 2018). Health coaching merupakan salah satu strategi yang dapat digunakan sebagai intervensi untuk mendorong dan memberdayakan pasien dalam memilih gaya hidup yang lebih sehat dengan mempromosikan pengelolaan kondisi yang lebih baik (Oliveira et al., 2017).

Dari 5 artikel yang disintesis, didapatkan 3 artikel menggunakan telepon yang membahas self-care management, kualitas hidup, hasil klinis dan status kesehatan pasien HF, menerima perawatan biasa, health coaching, dan booklet tentang HF sebagai panduan dan materi (Dwinger et al., 2020; Tiede et al., 2017; Wang et al., 2017), 1 artikel menggunakan metode diskusi dengan tatap muka langsung yang mengulas selfcare management pasien dengan menggunakan teknik wawancara semi terstruktur dengan pertanyaan terbuka yang berfokus pada pasien (Meeker et al., 2019). Artikel lain menggunakan kombinasi telepon dan tatap muka yang membahas perawatan diri pasien dengan pendekatan motivational interviewing (Vellone et al., 2020). Intervensi health coaching dapat dievaluasi dengan jelas dan memadai dengan melihat hasil dari yang menggunakan kelompok kontrol dalam studi. Intervensi kelompok kontrol umumnya terdiri dari perawatan rutin HF dan perawatan standar yang dilakukan oleh perawat $(\mathrm{n}=$ 4) (Dwinger et al., 2020; Tiede et al., 2017; Vellone et al., 2020; Wang et al., 2017), perawat dan dokter sebagai penyedia layanan kesehatan di perawatan $(n=1)$ (Meeker et al., 2019). Dalam 1 studi, kelompok melibatkan pengasuh dalam menerima perawatan standar termasuk materi informasional dan pemeriksaan kesehatan pasien (Vellone et al., 2020).

Intervensi health coaching dengan pendekatan motivational interviewing memiliki efek signifikan dalam meningkatkan self-care management pasien HF pasien (Vellone et al., 2020). Metode motivational interviewing digunakan oleh health coach sebagai bagian dari intervensi health coaching, sangat efektif dan efisien dalam membimbing dan mendorong pasien untuk mencapai tujuan dalam melakukan perubahan self-care management berkelanjutan. Begitu pula penelitian yang dilakukan oleh (Meeker et al., 2019) pada studi kualitatif melalui diskusi kelompok terarah dengan pendekatan motivational interviewing, menemukan bahwa sebagian besar pasien memahami keparahan kondisi mereka dan merasa perlu patuh terhadap asupan obat yang diresepkan, diet rendah garam yang dianjurkan, serta latihan fisik yang memadai dengan kondisi mereka.

Jumlah durasi intervensi health coaching berbeda-beda pada setiap studi, mulai dari durasi 2 bulan hingga 12 bulan. Umumnya durasi studi yang dilaksanakan adalah 12 bulan $(n=2)$. Studi yang menggunakan durasi intervensi paling pendek adalah studi yang dilakukan oleh Wang et al., (2017) yaitu 2 bulan, sedangkan durasi intervensi yang paling panjang adalah studi dengan durasi hingga 12 bulan (Dwinger et al., 2020; Vellone et al., 2020). Perubahan perilaku yang signifikan dilaporkan dalam 2 bulan, 3 
bulan, dan 12 bulan. Begitu pula dengan media pengiriman intervensi bervariasi. Secara keseluruhan, studi menggunakan telepon, tatap muka, dan kombinasi telepon dan tatap muka. Penggunaan media seluler termasuk telepon merupakan metode komunikasi jarak jauh yang lebih efektif dan efisien untuk memantau secara langsung pasien dalam melakukan program yang diberikan (Dwinger et al., 2020). Sejalan dengan penelitian yang menemukan bahwa teknologi seluler dan nirkabel semakin banyak digunakan dalam intervensi perawatan pasien di seluruh dunia dan memungkinkan untuk memfasilitasi akses yang lebih aman dan mudah ke layanan perawatan (Hamilton et al., 2018; Allida et al., 2020).

Penelitian menunjukkan bahwa intervensi health coaching meningkatkan self-care management secara signifikan terkait diet rendah garam, aktivitas fisik, kepatuhan pengukuran berat badan dan tekanan darah, serta kepatuhan pengobatan. Namun, penilaian terhadap hubungan dengan komponen health coaching yang digunakan tidak menunjukkan hubungan signifikan (termasuk durasi dan media pengiriman), intervensi health coaching dengan menggunakan metode PATCH tidak berdampak pada pengetahuan self-care management pasien pada akhir studi, begitu pula dengan studi kualitatif dianggap tidak memadai dalam mengubah pola perilaku dan keterampilan pasien dalam memperbaiki kondisi kesehatannya.

\section{SIMPULAN}

Intervensi health coaching telah digunakan diberbagai penelitian dan telah diterapkan di pelayanan kesehatan untuk dapat meningkatkan self-care management pasien HF. Meskipun komponen program health coaching yang berbeda-beda (jumlah durasi dan media pengiriman), namun hasil pada self-care management dan perubahan perilaku pasien terjadi peningkatan yang signifikan. Health coaching dapat dengan mudah melalui telepon, tatap muka, bahkan melalui web (telehealth/telemonitoring), maupun kombinasi dari ketiganya.

\section{SARAN}

Eksplorasi lebih lanjut diperlukan untuk menentukan efek health coaching pada hasil self-care management pasien HF yang berfokus pada penetapan metode yang sama, termasuk jumlah durasi, media pengiriman, dan tempat pelaksanaan health coaching.

\section{DAFTAR PUSTAKA}

Abbasi, A., Ghezeljeh, N. T., \& Farahani, A. M. (2018). Effect of the Self-Management Education Program on the Quality of Life in People with Chronic Heart Failure : A Randomized Controlled Trial. Electronic Physician, 10(7), 7028-7037. https://doi.org/10.19082/7028

Allida, S., Du, H., Xu, X., Prichard, R., Chang, S., Hickman, L. D., Davidson, P. M., \& Inglis, S. C. (2020). Health Education Interventions in Heart Failure . Cochrane Database of Systematic Reviews, 2020(7). https://doi.org/10.1002/14651858.CD011845.pub2

An, S., \& Song, R. (2020). Effects of Health Coaching on Behavioral Modification among Adults with Cardiovascular Risk Factors: Systematic Review and MetaAnalysis. Patient Education and Counseling, 2019. https://doi.org/10.1016/j.pec.2020.04.029 
Artama, S., Rachmawaty, R., \& Sinrang, A. W. (2017). Evaluasi Perubahan Self Care dan Quality of Life pada Pasien Chronic Heart Failure (Chf) yang Diberikan Health Education Programme di RSP. Universitas Hasanuddin Makassar. JST Kesehatan, 7(2), 178-184

Athar, M. W., Record, J. D., Martire, C., Hellmann, D. B., \& Ziegelstein, R. C. (2018). The Effect of a Personalized Approach to Patient Education on Heart Failure Self-Management. Journal of Personalized Medicine, 8(4). https://doi.org/10.3390/jpm8040039

Benjamin, E. J., Muntner, P., Alonso, A., Bittencourt, M. S., Callaway, C. W., Carson, A. P., Chamberlain, A. M., Chang, A. R., Cheng, S., Das, S. R., Delling, F. N., Djousse, L., Elkind, M. S. V., Ferguson, J. F., Fornage, M., Jordan, L. C., Khan, S. S., Kissela, B. M., Knutson, K. L., \& Virani, S. S. (2019). Heart Disease and Stroke Statistics-2019 Update: A Report From the American Heart Association. In Circulation, 139(10). https://doi.org/10.1161/CIR.0000000000000659

Boyde, M., Peters, R., New, N., Hwang, R., Ha, T., \& Korczyk, D. (2017). Self-Care Educational Intervention to Reduce Hospitalisations in Heart Failure : A Randomised Controlled Trial. European Society of Cardiology. https://doi.org/10.1177/1474515117727740

Crespo-Leiro, M. G., Metra, M., Lund, L. H., Milicic, D., Costanzo, M. R., Filippatos, G., Gustafsson, F., Tsui, S., Barge-Caballero, E., De Jonge, N., Frigerio, M., Hamdan, R., Hasin, T., Hülsmann, M., Nalbantgil, S., Potena, L., Bauersachs, J., Gkouziouta, A., Ruhparwar, A., \& Ruschitzka, F. (2018). Advanced Heart Failure : A Position Statement of the Heart Failure Association of the European Society of Cardiology. European Journal of Heart Failure , 20(11), 1505-1535. https://doi.org/10.1002/ejhf.1236

Dejonghe, L. A. L., Becker, J., Froboese, I., \& Schaller, A. (2017). Long-Term Effectiveness of Health Coaching in Rehabilitation and Prevention: A Systematic Review. Patient Education and Counseling, 100(9), 1643-1653. https://doi.org/10.1016/j.pec.2017.04.012

Di-Palo, K. E., Piña, I. L., \& Ventura, H. O. (2018). Improving Provider Adherence to Guideline Recommendations in Heart Failure . Current Heart Failure Reports, 15(6), 350-356. https://doi.org/10.1007/s11897-018-0411-y

Dwinger, S., Rezvani, F., Kriston, L., Herbarth, L., Härter, M., \& Dirmaier, J. (2020). Effects of Telephone-Based Health Coaching on Patient-Reported Outcomes and Health Behavior Change: A Randomized Controlled Trial. PLoS ONE, 15(9 September), 1-25. https://doi.org/10.1371/journal.pone.0236861

Dye, C., Willoughby, D., Aybar-Damali, B., Grady, C., Oran, R., \& Knudson, A. (2018). Improving Chronic Disease Self-Management by Older Home Health Patients Through Community Health Coaching. International Journal of Environmental Research and Public Health, 15(4), 1-24. https://doi.org/10.3390/ijerph15040660

Eriksen, M. B., \& Frandsen, T. F. (2018). The Impact of PICO as a Search Strategy Tool on Literature Search Quality: A Systematic Review. Journal of the Medical Library Association, 106(4), 420-431.

Grady, P. A., \& Gough, L. L. (2018). Self-Management: A Comprehensive Approach to Management of Chronic Conditions. American Journal of Public Health, 108(8), S430-S436. https://doi.org/10.2105/AJPH.2014.302041 
Hale, R., \& Giese, J. (2017). Cost-Effectiveness of Health Coaching: An Integrative Review. Professional Case Management, 22(5), 228-238. https://doi.org/10.1097/NCM.0000000000000223

Hamilton, S. J., Mills, B., Birch, E. M., \& Thompson, S. C. (2018). Smartphones in the Secondary Prevention of Cardiovascular Disease: A Systematic Review. BMC Cardiovascular Disorders, 18(1), 1-23. https://doi.org/10.1186/s12872-018-0764$\mathrm{x}$

Hastuti, A. P. (2019). Pengaruh Health Coaching Berbasis Teori Health Belief Model terhadap Tekanan Darah pada Lansia dengan Hipertensi. Journal of Islamic Medicine, 3(2), 1-8. https://doi.org/10.18860/jim.v3i2.8238

Meeker, D., Goldberg, J., Kim, K. K., Peneva, D., De, H., Campos, O., Maclean, R., Selby, V., \& Doctor, J. N. (2019). Patient Commitment to Health (PACT-Health) in the Heart Failure Population: A Focus Group Study of an Active Communication Framework for Patient-Centered Health Behavior Change Corresponding Author : 21. https://doi.org/10.2196/12483

Oliveira, J. S., Sherrington, C., Amorim, A. B., Dario, A. B., \& Tiedemann, A. (2017). What is the Effect of Health Coaching on Physical Activity Participation in People Aged 60 Years and Over? A Systematic Review of Randomised Controlled Trials. 1-9. https://doi.org/10.1136/bjsports-2016-096943

Riegel, B., Moser, D. K., Buck, H. G., VaughanDickson, V., Dunbar, S., Lee, C. S., Lennie, T. A., Lindenfeld, J. A., Mitchell, J. E., Treat-Jacobson, D. J., \& Webber, D. E. (2017). Self-Care for the Prevention and Management of Cardiovascular Disease and stroke: A scientific statement for healthcare professionals from the American Heart Association. Journal of the American Heart Association, 6(9), 127. https://doi.org/10.1161/JAHA.117.006997

Riskesdas. (2018). Hasil Utama Riset Kesehatan Dasar. Kementrian Kesehatan Republik Indonesia, 1-100. https://doi.org/1

Rossignol, P., Hernandez, A. F., Solomon, S. D., \& Zannad, F. (2019). Heart Failure Drug Treatment. The Lancet, 393(10175), 1034-1044. https://doi.org/10.1016/S0140-6736(18)31808-7

Sevilla-Cazes, J., Ahmad, F. S., Bowles, K. H., Jaskowiak, A., Gallagher, T., Goldberg, L. R., Kangovi, S., Alexander, M., Riegel, B., Barg, F. K., \& Kimmel, S. E. (2018). Heart Failure Home Management Challenges and Reasons for Readmission: a Qualitative Study to Understand the Patient's Perspective. Journal of General Internal Medicine, 33(10), 1700-1707. https://doi.org/10.1007/s11606-018-4542-3

Tiede, M., Dwinger, S., Herbarth, L., Härter, M., \& Dirmaier, J. (2017). Long-Term Effectiveness of Telephone-Based Health Coaching for Heart Failure Patients: A Post-Only Randomised Controlled Trial. Journal of Telemedicine and Telecare, 23(8), 716-724. https://doi.org/10.1177/1357633X16668436

Veen, E. V., Bovendeert., J. F. M., Backx., F. J. G., \& Huisstede, B. M. A. (2017). ECoaching: New Future for Cardiac Rehabilitation? A Systematic Review. Patient Education and Counseling, 100(12), 2218-2230. https://doi.org/10.1016/j.pec.2017.04.017

Vellone, E., Rebora, P., Ausili, D., Zeffiro, V., Pucciarelli, G., Caggianelli, G., Masci, S., Alvaro, R., \& Riegel, B. (2020). Motivational Interviewing to Improve SelfCare in Heart Failure Patients (Motivate-HF): A Randomized Controlled Trial. ESC Heart Failure , 7(3), 1309-1318. https://doi.org/10.1002/ehf2.12733 
Wang, Q., Dong, L., Jian, Z., \& Tang, X. (2017). Effectiveness of a Precede-Based Education Intervention on Quality of Life in Elderly Patients with Chronic Heart Failure . BMC Cardiovascular Disorders, 17(1), 1-7. https://doi.org/10.1186/s12872-017-0698-8 